\title{
DITERPENES AND RELATED CYCLOADDUCTS FROM TAIWANIA CRYPTOMERIOIDES
}

\author{
WANG-HoNG Lin, JiM-MIN FANG and YU-SHIA CHENG* \\ Department of Chemistry, National Taiwan University, Taipei, Taiwan 106, R. O. C.
}

(Received in revised form 9 January 1996)

Key Word Index-Taiwania cryptomerioides; Taxodiaceae; leaves; diterpenes.

\begin{abstract}
Seven new compounds were isolated from the leaves of Taiwania crypomerioides. Taiwaniaquinone D and taiwaniaquinone $E$ are diterpenes having a six-five-six fused ring skeleton. Taiwaniadduct $A$ is a $[4+2]$ cycloaddition product of $\beta$-myrcene and taiwaniaquinone $\dot{\mathrm{A}}$. Taiwaniadduct $\mathrm{B}$ and taiwaniadduct $\mathrm{C}$ are isomers derived from $[4+2]$ cycloadditions of trans-ozic acid and taiwaniaquinone $A$. Taiwaniadduct $D$ is formally an ene reaction product of taiwaniadduct $B$. Taiwaniadduct $E$ is a $[5+2]$ cycloaddition product of taiwaniaquinone $A$ and trans-ozic acid. The structure determination of these new compounds was based on spectral analyses and chemical transformation. A crystalline compound, prepared by bismethylation of taiwaniadduct $\mathrm{D}$, was analysed by X-ray diffraction to establish the stereochemistry.
\end{abstract}

\section{INTRODUCTION}

Taiwania cryptomerioides Hayata is an endemic evergreen species with thick linear-triangular leaves and elongate ovoid cones. The chemical constituents of this plant have been investigated extensively [1-3]. Various sesquiterpenes, lignans and bisflavones have been found in the leaves and wood. Four diterpenes (taiwaniaquinones $\mathrm{A}-\mathrm{C}$ and taiwaniaquinol $\mathrm{A}$ ) and one norditerpene (taiwaniaquinol $B$ ) having the unusual 6-5-6 fused ring skeleton were recently isolated [4]. We now report on a further two diterpenes, 1 and 2, of this type and five related terpenes (3-7) derived from the combination of taiwaniaquinone $\mathrm{A}$ with a monoterpene, $\beta$-myrcene, or a diterpene, trans-ozic acid.

\section{RESULTS AND DISCUSSION}

The acetone extract of the leaves of $T$. cryptomerioides was concentrated and taken up in chloroform. The soluble part was concentrated and subjected to chromatography to give compounds 1-7.

Compound 1 gave rise to a molecular ion $[\mathrm{M}]^{+}$at $\mathrm{m} / \mathrm{z} 328.168$ consistent with a molecular formula $\mathrm{C}_{20} \mathrm{H}_{24} \mathrm{O}_{4}$. The ${ }^{1} \mathrm{H}$ and ${ }^{13} \mathrm{C}$ NMR spectra (Table 1) indicated an aldehyde group $\left[\delta_{\mathrm{H}} 10.38(s)\right.$ and $\delta_{\mathrm{C}} 194.1$ $(d)]$ and two ketone groups $\left[\delta_{\mathrm{C}} 185.1(s)\right.$ and $\left.177.2(s)\right]$. The carbonyl groups were conjugated with olefinic double bonds as inferred from the IR absorptions at 1691 and $1630 \mathrm{~cm}^{-1}$ as well as the presence of six olefinic carbon signals at $\delta_{\mathrm{C}} 176.6(s), 152.2(s), 147.7$ $(s), 147.1(s), 134.4(s)$ and $123.2(s)$. Proton resonances for three methyl groups occurred at $\delta 1.14(s), 1.28(s)$ and $1.44(s)$, whereas those for an isopropyl group occurred at $\delta 1.18(d), 1.19(d)$ and 3.15 (sept). Compound 1 was given the trivial name taiwaniaquinone D, and its structure was finally elucidated by means of HMBC and HMQC. Treatment of taiwaniaquinone $\mathrm{B}$ (or taiwaniaquinone $\mathrm{C}$ ) with $\mathrm{AlCl}_{3}$ in $\mathrm{CH}_{2} \mathrm{Cl}_{2}$ yielded a dehydration product which was identified as taiwaniaquinione D (Scheme 1).

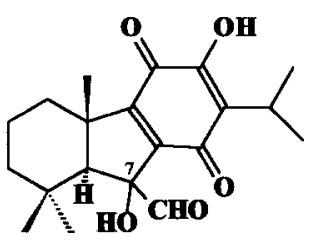

Taiwaniaquinone $\mathrm{B}, 7 \beta-\mathrm{OH}$

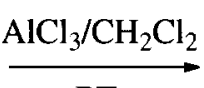

RT

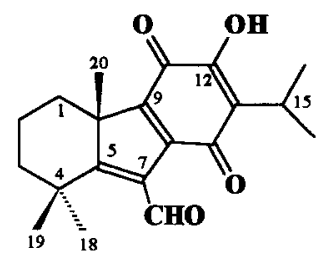

1 (Taiwaniaquinone D)

Scheme 1. Chemical synthesis of taiwaniaquinone D.

\footnotetext{
*Author to whom correspondence should be addressed.
} 
Table $1 .{ }^{13} \mathrm{C}$ and ${ }^{~} \mathrm{H}$ NMR spectral data of compounds 1 and $2\left(\mathrm{CDCl}_{3}, \delta\right.$ in ppm)

\begin{tabular}{|c|c|c|c|c|}
\hline & \multicolumn{2}{|r|}{1} & \multicolumn{2}{|r|}{2} \\
\hline & $\delta_{c}$ & $\delta_{\mathrm{H}}$ & $\delta_{\mathrm{C}}$ & $\delta_{\mathrm{H}}$ \\
\hline 1 & 35.2 & $2.40($ br d, 13.0)*† & 34.3 & $2.22(b r d, 12.0), 1.58(m)$ \\
\hline 2 & 18.3 & $1.68(m), 1.94(m)$ & 19.2 & $1.75(\mathrm{~m}), 1.62(\mathrm{~m})$ \\
\hline 3 & 43.3 & $1.72(m), 1.26(m)$ & 41.2 & $1.45(\mathrm{~m}), 1.22(\mathrm{~m})$ \\
\hline 4 & 38.0 & & 33.7 & \\
\hline 5 & 176.6 & & 62.4 & $2.13(d, 11.6)$ \\
\hline 6 & 194.1 & $10.38(s)$ & 174.2 & \\
\hline 7 & 134.4 & & 47.0 & $3.61(d, 11.6)$ \\
\hline 8 & 147.1 & & 148.5 & \\
\hline 9 & 147.7 & & 151.6 & \\
\hline 10 & 55.9 & & 48.0 & \\
\hline 11 & 177.2 & & 181.2 & \\
\hline 12 & 152.2 & & 151.1 & \\
\hline 13 & 123.2 & & 124.7 & \\
\hline 14 & 185.1 & & 185.2 & \\
\hline 15 & 24.0 & $3.15($ sept, 7.1$)$ & 24.0 & $3.10($ sept, 7.0$)$ \\
\hline 16 & 19.9 & $1.19(d, 7.1)$ & 19.8 & $1.14(d, 7.0)$ \\
\hline 17 & 19.9 & $1.18(d, 7.1)$ & 19.7 & $1.17(d, 7.0)$ \\
\hline 18 & 33.7 & $1.14(s)$ & 32.0 & $0.82(s)$ \\
\hline 19 & 25.6 & $1.28(s)$ & 21.4 & $1.03(s)$ \\
\hline 20 & 21.3 & $1.44(s)$ & 19.9 & $1.10(s)$ \\
\hline $\mathrm{CO}_{2} \mathrm{CH}_{3}$ & & & 52.3 & $3.73(s)$ \\
\hline
\end{tabular}

*The signal of the other proton was too weak to be assigned.

tCoupling constants $(J$ in $\mathrm{Hz})$ in parentheses.

Compound $2\left(\mathrm{C}_{21} \mathrm{H}_{28} \mathrm{O}_{5}\right)$ exhibited characteristic spectroscopic properties of a $p$-quinone moiety, i.e. UV absorption at $431 \mathrm{~nm}$, IR absorption at $1635 \mathrm{~cm}^{-1}$ and NMR at $\delta 185.2(s), 181.2(s), 151.6(s), 151.1(s)$, $148.5(s)$ and $124.7(s)$. A methyl ester group was inferred from the IR absorption at $1735 \mathrm{~cm}^{-1}$, the proton resonance at $\delta 3.73(\mathrm{~s})$, and the carbon signals at $\delta 174.2(s)$ and $52.3(q)$. Compound 2 is named taiwaniaquinone $\mathrm{E}$, and its structure is similar to that of taiwaniaquinone A, except for the aldehyde group in the latter structure being replaced with a methoxycarbonyl group. The proton and carbon resonances were assigned according to the HMBC and HMQC spectra. The stereochemistry was established from NOE studies. Thus, irradiation of $\mathrm{H}-18(\delta 0.82)$ caused an $11 \%$ enhancement of $\mathrm{H}-5(\delta 2.13)$ and irradiation of $\mathrm{H}-20$ $(\delta 1.10)$ caused a $15 \%$ enhancement of $\mathrm{H}-7$ ( $\delta 3.61)$.

Compound 3 was given the trivial name taiwaniadduct $\mathrm{A}$, and its structure was determined by chemical and spectral methods. The exact mass of the molecular ion $[\mathrm{M}]^{+}(\mathrm{m} / z$ 466.309) indicated a molecular formula $\mathrm{C}_{30} \mathrm{H}_{42} \mathrm{O}_{4}$. The proton and carbon signals (Table 2) were assigned according to the HMBC and HMQC

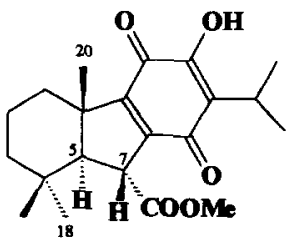

2 spectra. Triterpene 3 was presumably derived from the $[4+2]$ cycloaddition of the monoterpene, $\beta$-myrcene, and the diterpene, taiwaniaquinone $A$ (Scheme 2). The stereochemistry was deduced from NOE studies. For example, irradiation of H-6 ( $\delta 9.94)$ caused an $8 \%$<smiles>CC(C)C1=C(O)C(=O)C2=C(C1=O)[C@H](C=O)[C@]1(C(C)C)C(C)(C)CCC[C@]21C</smiles>

Taiwaniaquinone A

$\beta$-Myrcene cat. $\mathrm{Eu}(\text { fod })_{3}$
$\mathrm{CH}_{2} \mathrm{Cl}_{2}$
$\mathrm{RT}$

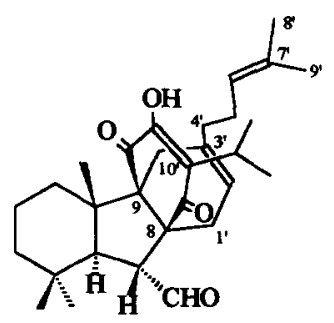
3

Scheme 2. Chemical synthesis of compound 3 . 
enhancement of $\mathrm{H}^{-1} \mathrm{l}^{\prime}(\boldsymbol{\delta} 2.34)$, indicating that the monoterpene moiety and the aldehydr group were on the same face. The Diels-Alder reaction $[5,6]$ between taiwaniaquinone $\mathrm{A}$ and $\boldsymbol{\beta}$-myrcene was promoted by a Lewis acid $\mathrm{Eu}$ (fod) ${ }_{3}$ to give a single product identical to 3 . The reaction occurred in a regio- and stereospecific manner, i.e. $\beta$-myrcene attacked the less hindered $\alpha$-face of taiwaniaquinone A to form C8-C1' and $\mathrm{C} 9-\mathrm{C} 10^{\prime}$ bonds. The 10-methyl group of taiwaniaquinone $A$ presumably hindered a $\beta$-face approach by $\beta$-myrcene. The regio-isomer with $\mathrm{C} 8-\mathrm{C} 10^{\prime}$ and $\mathrm{C} 9-\mathrm{Cl}^{\prime}$ bonds was not formed, becuase it would exert severe repulsion between the 13-isopropyl and 3'-alkyl groups.

Terpenes 4 (taiwaniadduct B) and 5 (taiwaniadduct C) were not readily purified. Compounds $4 \mathrm{~m}$ and $5 \mathrm{~m}$ obtained by bismethylation of 4 and $5\left(\mathrm{CH}_{2} \mathrm{~N}_{2}, \mathrm{Et}_{2} \mathrm{O}\right)$ were purified by HPLC and their structures were determined by spectroscopic methods (IR, MS, HRMS, and ${ }^{1} \mathrm{H},{ }^{13} \mathrm{C}, \mathrm{HMBC}$ and HMQC NMR). Compounds $4 \mathrm{~m}$ and $\mathbf{5 m}$ were isomers giving rise to molecular ions $[\mathrm{M}]^{+}$at 660.439 attributable to the molecular formula $\mathrm{C}_{42} \mathrm{H}_{60} \mathrm{O}_{6}$. The ${ }^{1} \mathrm{H}$ and ${ }^{1.3} \mathrm{C}$ NMR spectra of $4 \mathrm{~m}$ showed the characteristic resonances (Table 2) of an aldehyde group $\left[\delta_{\mathrm{H}} 9.60(d)\right.$ and $\delta_{\mathrm{C}} 205.4(d)$ ], a methyl ester $\left[\delta_{\mathrm{H}} 3.56(s), \delta_{\mathrm{C}} 51.8(q)\right.$ and $\left.178.9(s)\right]$, conjugated ketones $\left[\delta_{\mathrm{C}} 198.6(s)\right.$ and $\left.201.3(s)\right]$, a methoxy group $\left[\delta_{\mathrm{H}} 3.91(s)\right]$, a terminal double bond $\left[\delta_{\mathrm{C}} 108.7(t)\right.$ and $146.8(s)]$, a trisubstituted double bond $\left[\delta_{\mathrm{C}} 120.4(d)\right.$ and $144.2(s)$ ], as well as for a tetrasubstituted double bond $\left[\delta_{\mathrm{C}} 141.3(s)\right.$ and $\left.159.0(s)\right]$. The regio- and stereochemistry of $\mathbf{4 m}$ was supported by the NOESY spectrum. H-5 $(\delta 1.57)$ had NOE correlations with H-6 $(\delta 9.60)$ and $\mathrm{H}-12^{\prime}(\delta 3.10)$, whereas $\mathrm{H}-7(\delta 3.10)$ had a correlation to $\mathrm{H}-20(\delta 0.63)$, whereas the NOESY spectrum of $5 \mathrm{~m}$ showed the correlations of $\mathrm{H}-6$ $(\delta 9.50)$ to $\mathrm{H}-12^{\prime}(\delta 2.20), \mathrm{H}-5(\delta 1.79)$ to $\mathrm{H}-14^{\prime}$ $(\delta 5.55)$ and $\mathrm{H}-7(\delta 3.14)$ to $\mathrm{H}-20(\delta 0.73)$.

Compounds 4 and 5 were presumably derived from $[4+2]$ cycloadditions of the labdane diterpene, transozic acid, and taiwaniaquinone A (Scheme 3). Compound 4 had the linkages at $\mathrm{C} 8-\mathrm{C} 15^{\prime}$ and $\mathrm{C} 9-\mathrm{C} 12^{\prime}$, whereas compound 5 had the alternative linkages at C8-C12' and C9-C15'. The stereochemistry shown in 4 and 5 is consistent with cycloadditions of two components occurring at the less hindered faces and following the endo-selectivity of conventional Diels-Alder reactions.<smiles>C=CC(C)=CCC1C(=C)CCC2C(C)(C(=O)O)CCC[C@]12C</smiles>

trans-ozic acid

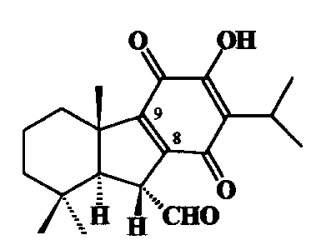

Taiwaniaquinone $\mathrm{A}$
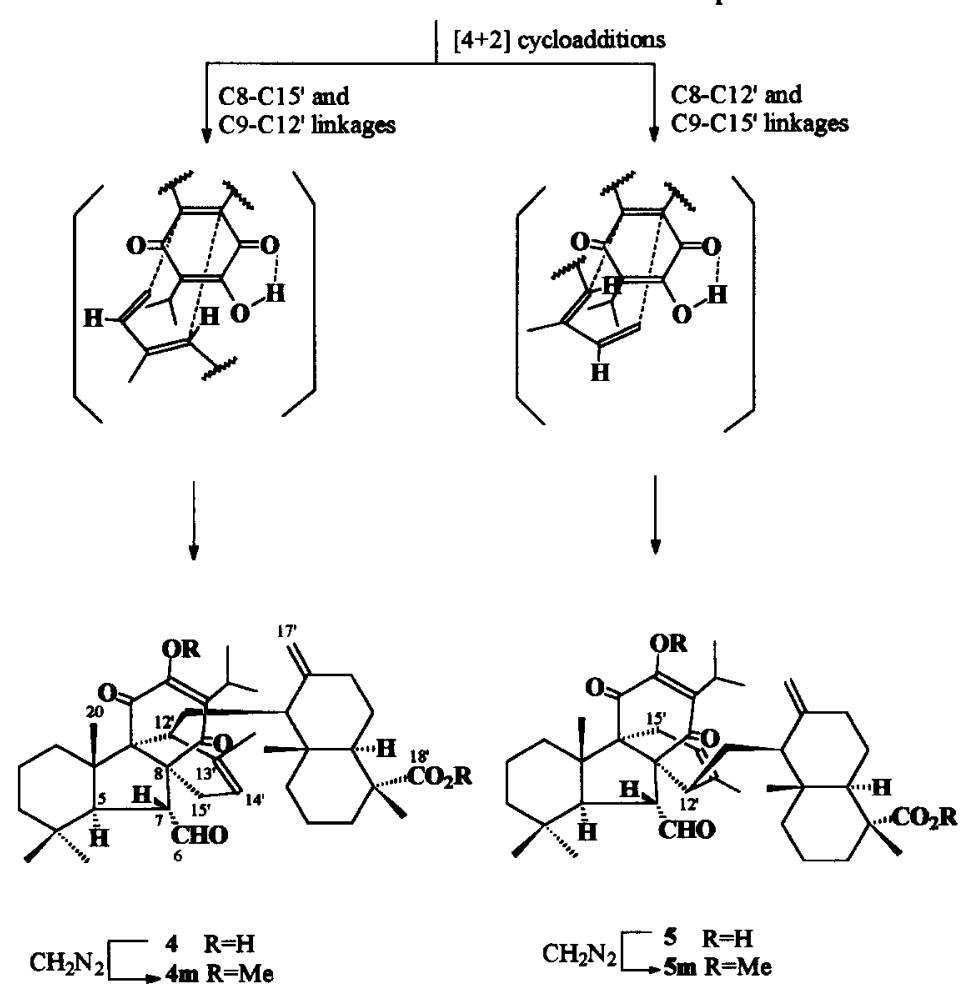

Scheme 3. Formation of compounds 4 and 5 . 


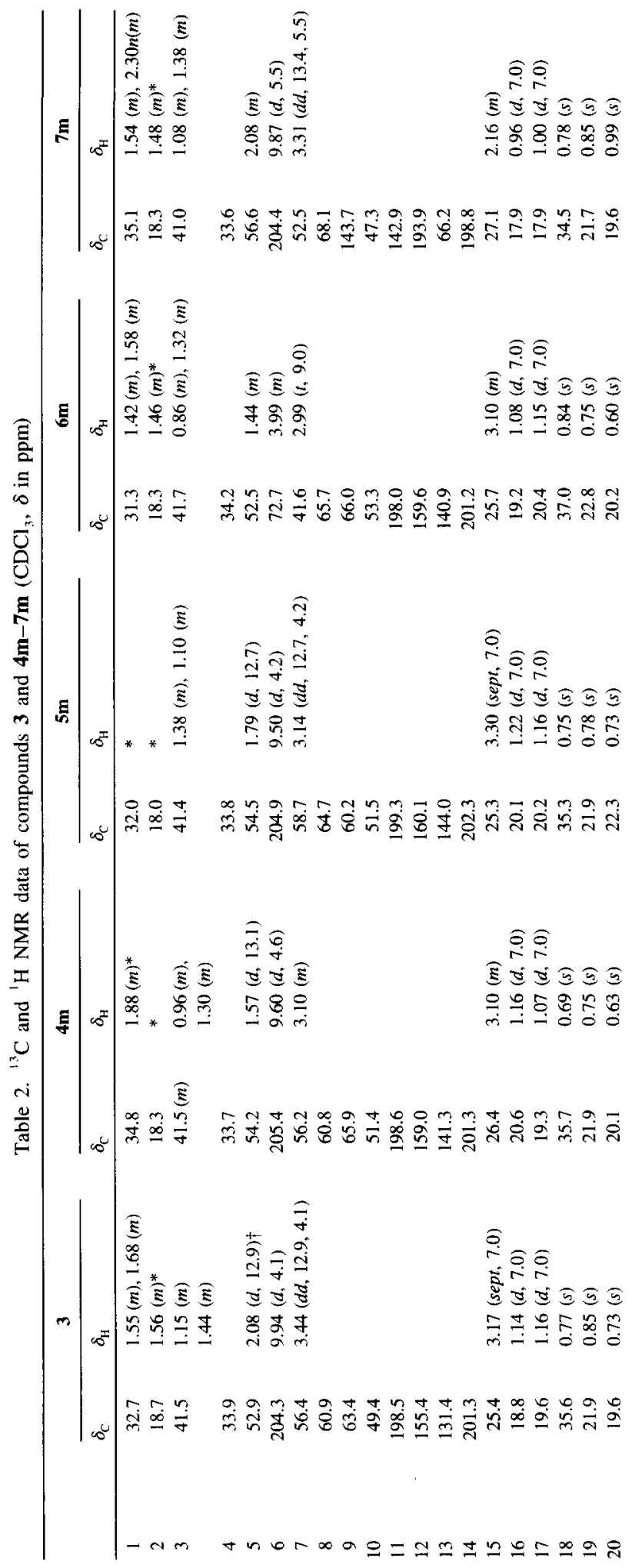




\begin{tabular}{|c|c|c|c|c|c|c|}
\hline & $\widehat{\underline{E}} \bar{E}$ & & $\widehat{\widehat{E}}$ & $\widehat{\bar{E}}$ & 3 & \\
\hline & స్తి & & & $\partial_{\partial}^{\infty} \overbrace{j}^{\infty}$ & $\mathscr{6}$ & \\
\hline 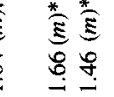 & 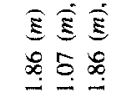 & $\begin{array}{l}\widehat{\widehat{E}} \\
\stackrel{0}{-}\end{array}$ & 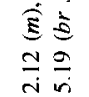 & 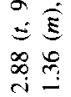 & 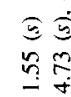 & \\
\hline 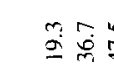 & 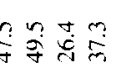 & 苾 & & & & \\
\hline
\end{tabular}

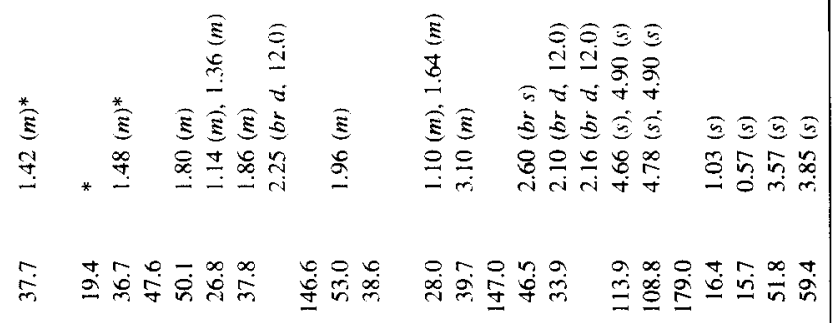

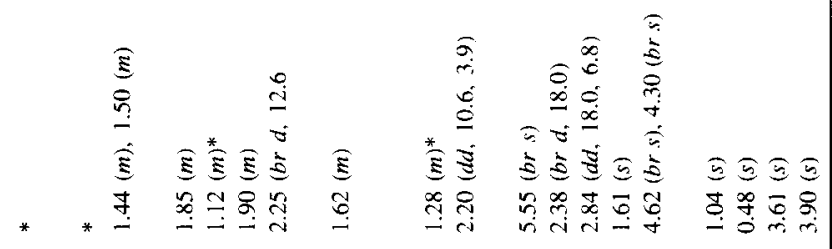

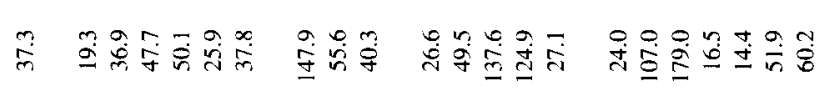

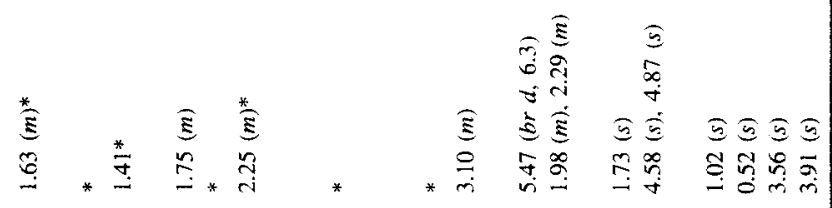

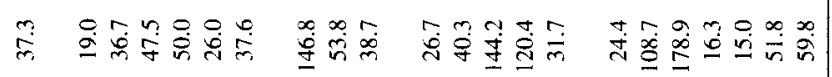
$\stackrel{n}{m}$ $\widehat{\bar{j}} \overline{\mathrm{g}}$

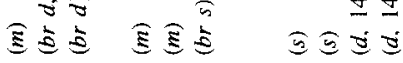

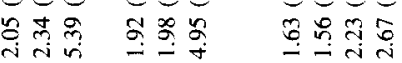

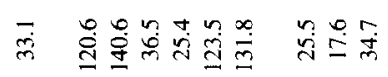

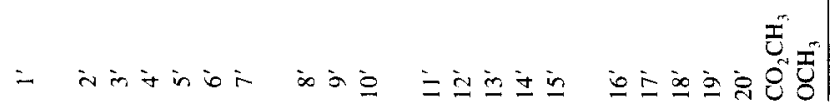



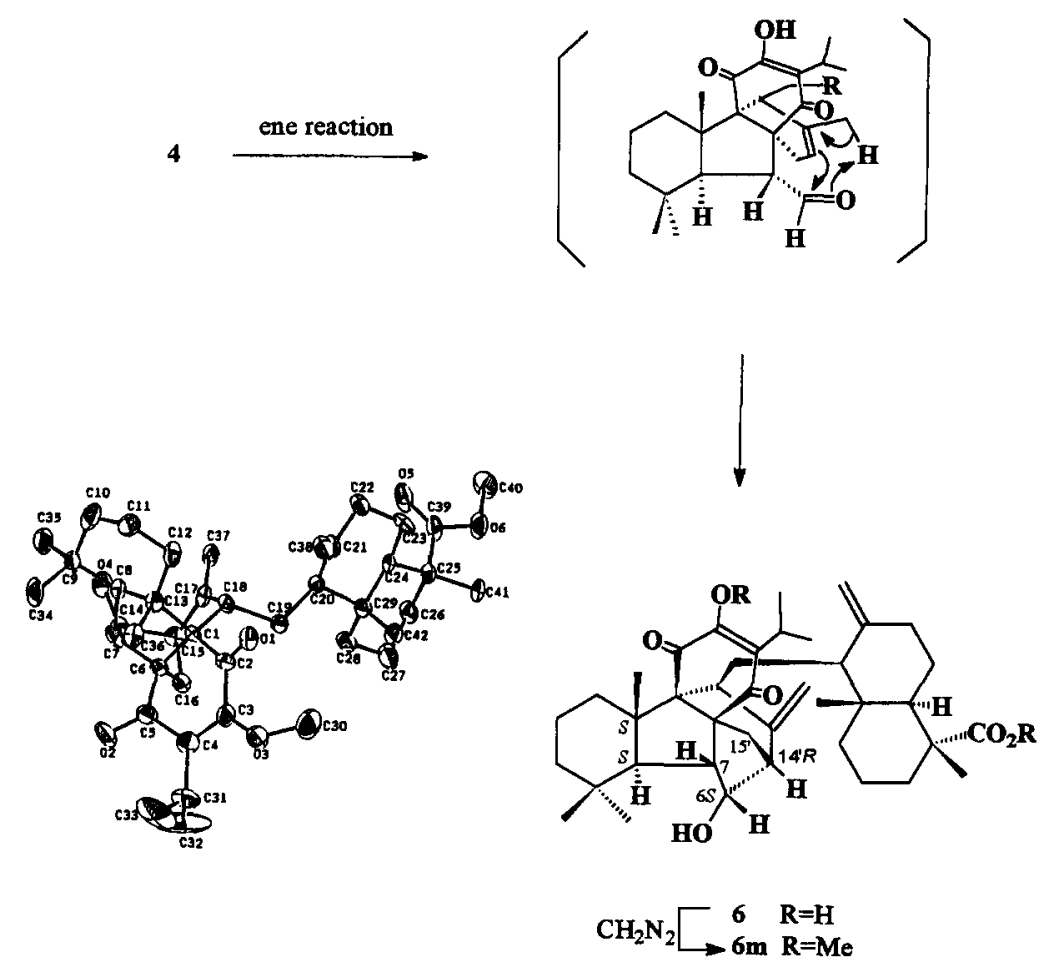

Scheme 4. Formation of compound 6 and ORTEP drawing of compound $6 \mathrm{~m}$.

Terpene 6 was treated with $\mathrm{CH}_{2} \mathrm{~N}_{2}$ to give a crystalline bismethylated compound, $6 \mathrm{~m}\left(\mathrm{C}_{42} \mathrm{H}_{60} \mathrm{O}_{6}\right)$, the structure of which was determined by an X-ray diffraction study along with other spectroscopic methods (IR, MS, and ${ }^{1} \mathrm{H},{ }^{13} \mathrm{C}$, HMBC and HMQC NMR). The NOESY spectrum also supported the assigned stereochemistry. Compound 6, namely taiwaniadduct D, was presumably derived from the ene reaction (allylcarbonyl coupling, for reviews see refs 7 and 8) of 4 (Scheme 4). The newly formed chiral centres had the $\left(6 S, 14^{\prime} R\right)$-configuration.

Terpene 7 was treated with $\mathrm{CH}_{2} \mathrm{~N}_{2}$ to give the corresponding methyl ester, $7 \mathbf{m}$, having a molecular ion $[\mathrm{M}]^{+}$at $\mathrm{m} / z \quad 646.423$ attributable to the molecular formula $\mathrm{C}_{41} \mathrm{H}_{58} \mathrm{O}_{6}$. The structure of $7 \mathbf{m}$ was determined by detailed analysis of the IR, MS, and ${ }^{1} \mathrm{H},{ }^{13} \mathrm{C}$, HMBC and HMQC NMR spectra. H-14' was in the proximity of the aldehyde group as indicated by the NOESY spectrum. The stereochemistry was similarly assigned: NOE correlations of H-6 ( $\delta$ 9.87) to H-5 $(\delta 2.08), \mathbf{H}-7(\delta 3.31)$ to $\mathrm{H}-20(\delta 0.99)$, and $\mathrm{H}-12^{\prime}$ $(\delta 5.19)$ to $\mathrm{H}-14^{\prime}(\delta 2.88)$ were observed. Compound 7, namely taiwaniadduct $E$, appeared to be derived from the $[5+2]$ cycloaddition [9] between taiwaniaquinone $\mathrm{A}$ and trans-ozic acid with the formation of linkages at $\mathrm{C} 8-\mathrm{C} 14^{\prime}$ and $\mathrm{C} 13-\mathrm{C} 15^{\prime}$ (Scheme 5). The alternative $[5+2]$ cycloaddition with the linkages at $\mathrm{C} 8-\mathrm{C} 15^{\prime}$ and C13-C14' was unfavourable presumably due to the severe repulsion between the isopropyl group at $\mathrm{C}-13$ and the methyl group at C-13'.

In summary, diterpenes 1 and 2 having a 6-5-6 fused ring skeleton were found in $T$. cryptomerioides, in addition to the previously reported analogs from this plant source. Compounds 3-7 were derived from taiwaniaquinone $\mathrm{A}, \beta$-myrcene and trans-ozic acid via $[4+2]$ cycloaddition, $[5+2]$ cycloaddition or an ene reaction. Since the enzymes for these reactions are not known in biological systems [10], compounds 3-7 are probably artefacts. It is, however, rather uncommon that combinations of taiwaniaquinone $A$ with $\beta$ myrcene or trans-ozic acid occurred during the separation procedure.

\section{EXPERIMENTAL}

General. HPLC: Hibar Lichrosorb Si 60 column ( $10 \mu \mathrm{m}, 25 \mathrm{~cm} \times 1 \mathrm{~cm}$ i.d.); TLC: Merck silica gel $60 \mathrm{~F}$ sheets.

Plant material. The dried leaves $(1.75 \mathrm{~kg})$ of $T$. cryptomerioides were exhaustively extracted with $\mathrm{Me}_{2} \mathrm{CO}(71 \times 3)$. The combined extracts were concd to ca $0.8 \mathrm{l}$, and taken up with $\mathrm{CHCl}_{3}(0.81 \times 3)$. The $\mathrm{CHCl}_{3}$-soluble portion was concd $(55 \mathrm{~g})$ and subjected to silica-gel $\mathrm{CC}$. The portion obtained from elution of EtOAc-hexane (5-40\%) was further subjected to flash chromatography and HPLC with elution of EtOAchexane $(5-30 \%)$ or EtOAc- $\mathrm{CH}_{2} \mathrm{Cl}_{2}(10 \%)$ to give compounds 1 (42 mg), 2 (26 mg), 3 (256 mg), 4 (298 mg), 5 (45 mg), 6 (311 mg) and 7 (256 mg). Acids 4-7 were further transformed into their corresponding methyl ester derivatives $\mathbf{4 m}-\mathbf{7 m}$, which were purified by HPLC.

Taiwaniaquinone $D(1)$. Red gum, $[\alpha]_{\mathrm{D}}^{22}-4.9^{\circ}$ $\left(\mathrm{CHCl}_{3} ; c 2.1\right.$ ). TLC (5\% EtOAc in hexane) $R_{f} 0.34$. 


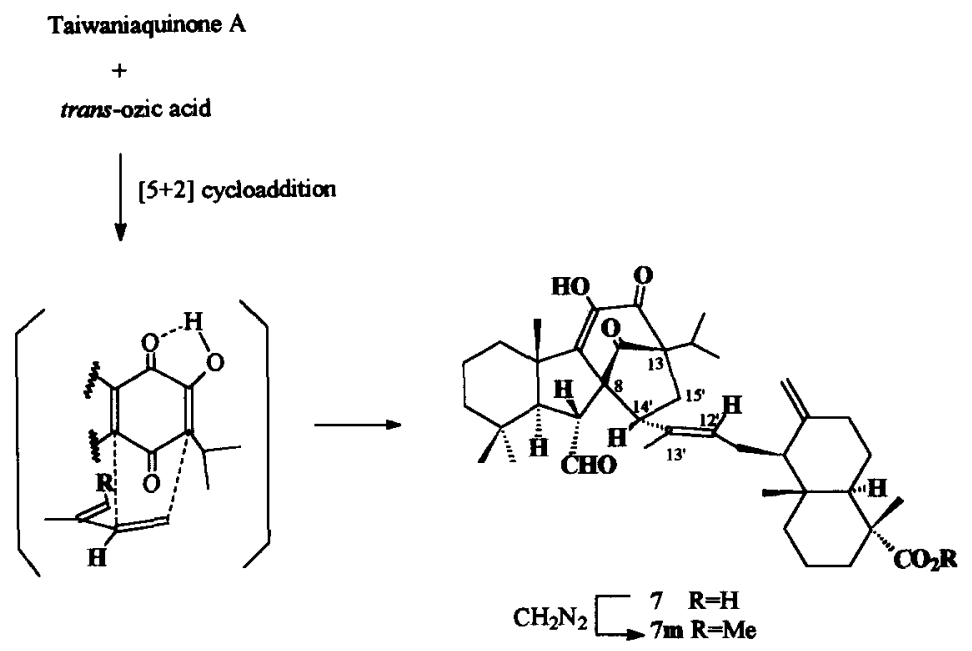

Scheme 5. Formation of compound 7.

IR $\nu_{\max }^{\mathrm{KBr}} \mathrm{cm}^{-1}: 3361,1691,1630 ; \mathrm{UV} \lambda_{\max }^{\mathrm{MeOH}} \mathrm{nm}(\varepsilon)$ : 477 (756), 340 (6410), 226 (12 655); EIMS (70 eV) $\mathrm{m} / \mathrm{z}$ (rel. int.): $328[\mathrm{M}]^{+}$(36), $300(20), 285(58), 259$ (100), 231 (14), 215 (8), 173 (6). HR-MS for $\mathrm{C}_{20} \mathrm{H}_{24} \mathrm{O}_{4}$ requires: 328.1675. Found: 328.1678.

Taiwaniaquinone $E(2)$. Yellow solid, mp: 79-81 , $[\alpha]_{\mathrm{D}}^{22}-204^{\circ}\left(\mathrm{CHCl}_{3} ; \quad c 1.3\right)$. TLC $(5 \%$ EtOAc in hexane) $R_{f} 0.25$. IR $\nu_{\max }^{\mathrm{KBr}} \mathrm{cm}^{-1}: 3383,1735,1635 ; \mathrm{UV}$ $\lambda_{\max }^{\mathrm{MeOH}} \mathrm{nm}(\varepsilon): 431$ (542), 341 (7911), 228 (15488); EIMS (70 eV) $\mathrm{m} / z$ (rel. int.): 360 [M] $^{+}$(30), 300 (100), 285 (30), 244 (10), 231 (22), 217 (18), 189 (12). HR-MS for $\mathrm{C}_{21} \mathrm{H}_{28} \mathrm{O}_{5}$ requires: 360.1937. Found: 360.1940 .

Taiwaniadduct A (3). Solid, mp: $128-129^{\circ},[\alpha]_{\mathrm{D}}^{20}$ $-106.3^{\circ}\left(\mathrm{CHCl}_{3} ; c\right.$ 12.8). TLC (5\% EtOAc in hexane) $R_{f} \quad 0.27$. IR $\nu_{\max }^{\mathrm{KBr}} \mathrm{cm}^{-1}: 3347,1711,1640 ; \mathrm{UV}$ $\lambda_{\max }^{\mathrm{MeOH}} \mathrm{nm}(\varepsilon): 345$ (4091), 290 (7017); EIMS (70 eV) $\mathrm{m} / \mathrm{z}$ (rel. int.): $466[\mathrm{M}]^{+}$(12), 449 (4), 384 (2), 300 (100), 257 (5), 231 (20), 217 (4). HR-MS for $\mathrm{C}_{30} \mathrm{H}_{42} \mathrm{O}_{4}$ requires: 466.3085 . Found: 466.3094 .

Taiwaniadduct $B(4)$. Compound $4(298 \mathrm{mg})$ was treated with $\mathrm{CH}_{2} \mathrm{~N}_{2}$ in $\mathrm{Et}_{2} \mathrm{O}$ to give the bismethylated compound $4 \mathrm{~m}(282 \mathrm{mg})$. Solid, mp: $158-160^{\circ},[\alpha]_{\mathrm{D}}^{25}$ $-15.6^{\circ}\left(\mathrm{CHCl}_{3} ; c 14.1\right)$. TLC (5\% EtOAc in hexane) $R_{f} 0.1$. IR $\nu_{\max }^{\mathrm{KBr}} \mathrm{cm}^{-1}: 1713,1657$; UV $\lambda_{\max }^{\mathrm{MeOH}} \mathrm{nm}(\varepsilon)$ : 304 (2309), 288 (2614), 204 (14 630); EIMS (70 eV) $m / z$ (rel. int.): $661[\mathrm{M}+1]^{+}(7), 660[\mathrm{M}]^{+}(1.5), 601$ (1.5), 494 (40), 412 (7), 259 (15), 246 (100). HR-MS for $\mathrm{C}_{42} \mathrm{H}_{60} \mathrm{O}_{6}$ requires: 660.4392 . Found: 660.4391 .

Taiwaniadduct $C$ (5). Compound 5 (45 mg) was treated with $\mathrm{CH}_{2} \mathrm{~N}_{2}$ in $\mathrm{Et}_{2} \mathrm{O}$ to give the bismethylated compound $5 \mathrm{~m}(40 \mathrm{mg})$. Solid, mp: $156-157^{\circ},[\alpha]_{\mathrm{D}}^{2 \mathrm{~s}}$ $-82.3^{\circ}\left(\mathrm{CHCl}_{3} ; c 2.0\right)$. TLC (5\% EtOAc in hexane) $R_{f}$ 0.1 IR $\nu_{\max }^{\mathrm{KBr}} \mathrm{cm}^{-1}: 1715,1658 ; \mathrm{UV} \lambda_{\max }^{\mathrm{MeOH}} \mathrm{nm}(\varepsilon): 282$ (5053), 202 (13 800); EIMS ( $70 \mathrm{eV}) \mathrm{m} / \mathrm{z}$ (rel. int.): 660 $[\mathrm{M}]^{+}(10), 600(5), 494(18), 410(25), 316(85), 247$ (50), 121 (100). HR-MS for $\mathrm{C}_{42} \mathrm{H}_{60} \mathrm{O}_{6}$ requires: 660.4392. Found: 660.4390 .

Taiwaniadduct $D(6)$. Compound $6(311 \mathrm{mg})$ was treated with $\mathrm{CH}_{2} \mathrm{~N}_{2}$ in $\mathrm{Et}_{2} \mathrm{O}$ to give the bismethylated compound $6 \mathrm{~m}$ (288 mg). Crystals from $\mathrm{MeOH}-$
$\mathrm{CH}_{2} \mathrm{Cl}_{2} \quad(1: 9), \quad \mathrm{mp}: \quad 210.5-212.0^{\circ}, \quad[\alpha]_{\mathrm{D}}^{25}-60.1^{\circ}$ $\left(\mathrm{CHCl}_{3} ; c 14.4\right)$. TLC (5\% EtOAc in hexane) $R_{f} 0.1$. IR $\nu_{\max }^{\mathrm{KBr}} \mathrm{cm}^{-1}: 3512,1710,1658$; UV $\lambda_{\max }^{\mathrm{MeOH}} \mathrm{nm}(\varepsilon): 279$ (8858), 202 (20 431). FAB (+) $661.7[\mathrm{M}+1]^{+}$. HRMS for $\mathrm{C}_{42} \mathrm{H}_{60} \mathrm{O}_{6}$ requires: 660.4392. Found: 660.4343.

Taiwaniadduct $E(7)$. Compound $7(256 \mathrm{mg})$ was treated with $\mathrm{CH}_{2} \mathrm{~N}_{2}$ in $\mathrm{Et}_{2} \mathrm{O}$ to give the monomethylated compound $7 \mathrm{~m}$ (222 mg). Solid, mp: 114 $116^{\circ},[\alpha]_{\mathrm{D}}^{25}+25.3^{\circ}\left(\mathrm{CHCl}_{3} ; c 11.1\right)$. TLC (5\% EtOAc in hexane) $R_{f} 0.1$. IR $\nu_{\max }^{\mathrm{KBr}} \mathrm{cm}^{-1}: 3418,1753,1721$, 1668, 1627; UV $\lambda_{\max }^{\mathrm{MeOH}} \mathrm{nm}(\varepsilon): 286 \quad(7661), 202$ (27 140). FAB $(+)$ 647.3 $[\mathrm{M}+1]^{+}$. HR-MS for $\mathrm{C}_{41} \mathrm{H}_{58} \mathrm{O}_{6}$ requires: 646.4235. Found: 646.4225 .

Acknowledgement-We thank the National Science Council for financial support.

\section{REFERENCES}

1. Kamil, M., Ilyas, M., Rahman, W., Hasaka, N. Okigawa, M. and Kawano, N. (1981) J. Chem. Soc., Perkin Trans. I 553.

2. Kuo, Y.-H., Chen, W.-C. and Lin, Y.-T. (1987) Chem. Express 2, 105.

3. Fang, J.-M. and Cheng, Y.-S. (1992) J. Chin. Chem. Soc. (Taipei) 39, 647.

4. Lin, W.-H., Fang, J.-M. and Cheng, Y.-S. (1995) Phytochemistry 40871.

5. Majetich, G. and Zhang, Y. (1994) J. Am. Chem. Soc. 116, 4979.

6. Trost, B. M., O'Krongly, D. and Bellatire, J. L. (1980) J. Am. Chem. Soc. 102, 7595.

7. Hoffmann, H. M. R. (1969) Angew. Chem., Int. Ed. Engl. 8, 556.

8. Oppolzer, W. (1981) Pure Appl. Chem. 53, 1181.

9. Walls, F., Padilla, J., Joseph-Nathan, P., Giral, F. and Romo, J. (1965) Tetrahedron Letters 1577.

10. Oikawa, H., Katayama, K., Suzuki, Y. and Ichihara, A. (1995) J. Chem. Soc., Chem. Commun. 1321. 